\title{
Migraciones POSMOdERnAS EN ChILE: REFLEXIONES SOBRE COHESIÓN SOCIAL Y PLURALIDAD CULTURAL $^{1}$
}

\author{
Postmodern Migration in CHILE: \\ REFLECTIONS ABOUT SOCIAL COHESION AND CULTURAL PLURALISM
}

Por: Lorenzo Agar Corbinos*

Artículo recibido: Noviembre 28 de 2011. Artículo aprobado: Febrero 13 de 2012

*LORENZO AGAR

CORBINOS

Es sociólogo, con un Magíster en Planificación del

Desarrollo Urbano y ReDesarrollo Urbano y Regional, tiene un Master y un Diploma de Estudios Avanzados en la Universidad de Paris Vincennes y un doctorado en Ciencias Sociales por la Universidad Paris Descartes. Actualmen-

te es Profesor Agrega do

la Escuela de Salud Pública de la Facultad de Medicin de la Universidad de Chile. Es docente invitado en la Universidad del Magdalen y la Universidad de Cartagena en donde participa en el grupo de investigaen el grupo de investig cion "Estudios de Familias, Masculinidades y Feminidades" reconocido por Colciencias en la categoría C. Lorenzoagar@gmail.com

Artículo de reflexión según clasificación Colciencias.

1 Este artículo ha sido escrito sobre la base de un capítulo de la tesis con la que su autor obtuvo e grado de Doctor en Ciencias grado de Doctor en Ciencias Saris Descartes (Sorbona) de Paris Descartes (Sorbona) en 2011. El título de la tesis es: Migraciones internacionales y diversidad cultural en Chile: los desafíos de la posmodernidad (en francés, 445 págs).

\section{RESUMEN}

Las migraciones internacionales son uno de los temas de mayor relevancia en los inicios del siglo XXI. Las naciones receptoras de inmigrantes deben velar por generar equitativas condiciones de vida para el conjunto de la población. Hoy en día estamos en medio de una gran paradoja: por un lado la globalización que pretende uniformizar y por otro la reivindicación de las particularidades culturales de cada pueblo. En este artículo se ejemplifica las nuevas migraciones con el caso chileno pues se evidencia un importante flujo inmigratorio en las dos últimas décadas lo cual plantea los problemas de la inserción de los grupos culturales foráneos en un ambiente local con una tendencia histórica a la representación social de un homogéneo (el Uno simbólicamente en nuestro texto) mas que transita con fuerza hacia ambientes de pluralidad cultural, en un contexto de globalización y posmodernidad que hemos representado por la emergencia del Tres. Es esta tensión social la que hemos expresado en este texto como una forma de motivar el pensamiento reflexivo en torno a los tránsitos hacia una sociedad más abierta ideológicamente, diversa culturalmente e imperativamente más participativa y dialogante.

Palabra clave: migraciones, globalización, posmodernidad, cohesión social, pluralidad cultural.

\section{ABSTRACT}

International migration is one of the most relevant topics studied at the beginning of the XXI century. Nations hosting immigrants might guarantee that there are conditions for a good quality of life and that they also offer equal opportunities to the whole population. Examining this migration phenomenon, we notice that nowadays we are between two opposite views: one that is in favor of globalization and pretends to unify the society; another that defends cultural differences. In order to illustrate the problems that immigrants entering a new local communities face, this article exemplifies via the Chilean case, how this migratory flux of people has occurred during the last two decades. In Chile, we have found that there is a historical trend to show these migratory communities as a homogenous group (group One in our reading) that moves to environments of cultural pluralism, spaces living in a context of globalization and post-modernity (represented in our reading as a result of an emergence of a group Three). This social tension is the one we have examined in this article. Our purpose is to encourage our academic community to reflect about our own transition to a society more open to cultural diversity, and as a result, to become active members to dialogue with other communities and cultures.

Key Words: migration, globalization, post-modernity, social cohesion, cultural pluralism. 


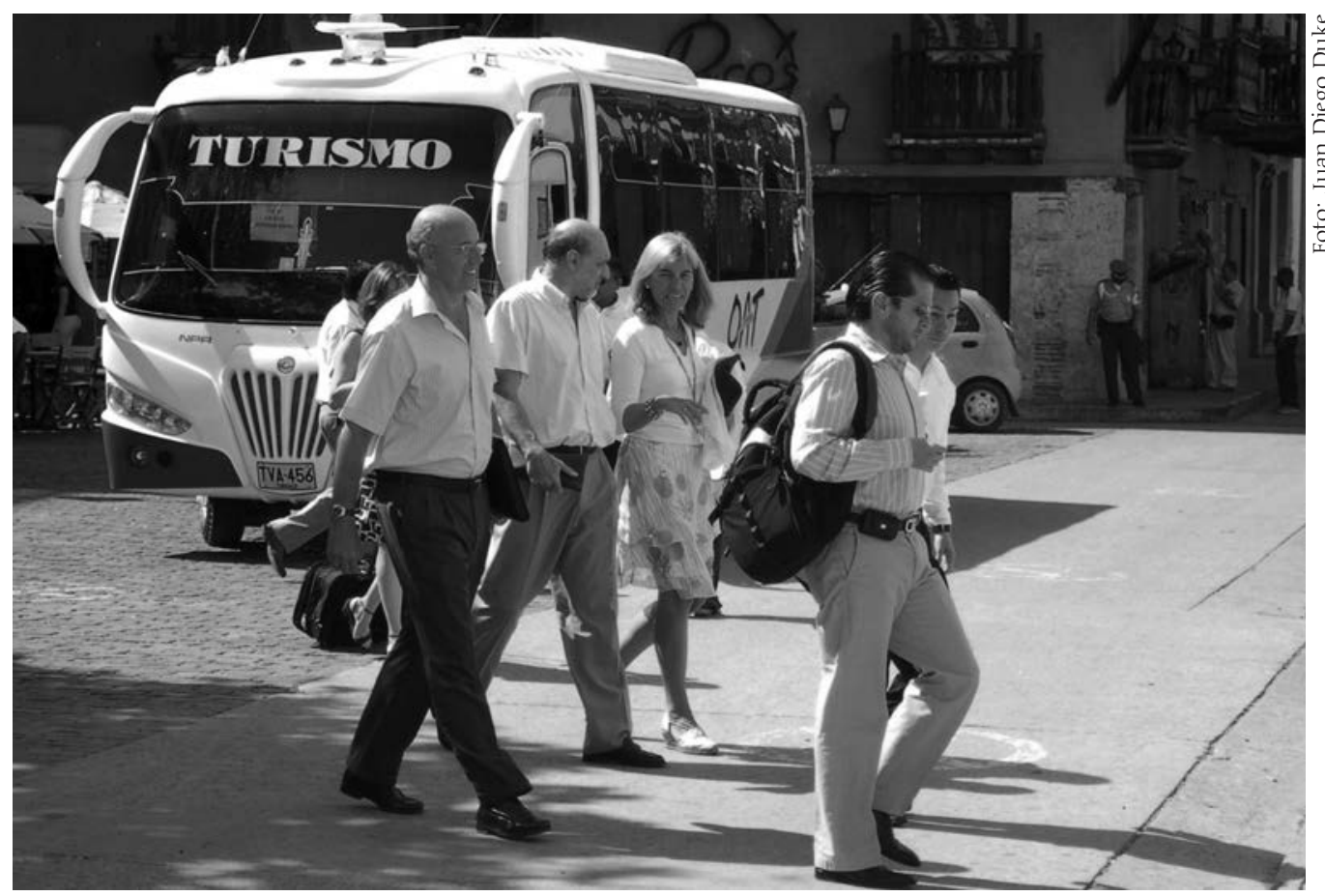

Extranjeros en la plaza 2012

\section{INTRODUCCIÓN}

Una mirada atenta a los grandes asuntos sociodemográficos que marcan la entrada en el nuevo milenio nos muestra los siguientes temas como los de mayor relevancia por su impacto en las transformaciones sociales, económicas y políticas contemporáneas; estos son: el envejecimiento de la población, la implosión urbana y las migraciones internacionales. Entre mediados del siglo XX y hoy día el mundo ha presentado grandes cambios en las tendencias poblacionales: la fecundidad ha visto reducir en dos el número de hijos por mujer; la esperanza de vida ha aumentado en veinte años; la mortalidad infantil ha decrecido en un 65 por ciento; la urbanización se ha duplicado, representando actualmente a la mitad de la población mundial. Y los migrantes internacionales se han duplicado en tan solo 25 años. Hoy representan un tres por ciento de la población mundial. En las últimas dos décadas son los países desarrollados quienes han acaparado las preferencias como lugares de destino. Los movimientos migratorios internacionales se concentran actualmente en unos pocos países: por cada diez inmigrantes en el mundo tres residen en Europa Occidental y dos en los EEUU de Norteamérica.

Coherente con la creciente urbanización, los migrantes internacionales se han localizado preferentemente en las denominadas "ciudades globales". Estas grandes urbes se han convertido crecientemente en puntos de convergencia 
del poder económico y político. Asimismo, administran la riqueza y producen el conocimiento de vanguardia que sostiene y posibilita el desarrollo.

Es innegable que en la migración conviven un conjunto de determinantes sociales que son de difícil precisión y que dicen relación con la realidad objetiva de mundos dispares y, cómo obviarlo, con la percepción individual basada en relatos e imágenes que se van creando y transmitiendo boca a boca, ahora con ayuda de la tecnología de las comunicaciones, que en forma creciente se pone al alcance de un mayor número de personas.

Las personas tienen derecho a emigrar de los lugares que han nacido, de igual forma que lo tienen para desarrollar una vida digna en sus países de nacimiento. Ambos son derechos humanos y cualquiera sea la situación, elegida libremente, condicionada socialmente o forzada por distintas razones, es deber de las naciones emisoras y receptoras de migrantes velar por adecuadas condiciones de vida, en especial en aquellos aspectos tan sensibles como lo son la salud, la educación y la cohesión social, entre otras.

Una de las paradojas de la globalización con efecto en las migraciones apunta, por un lado, a la tendencia a la homogenización de las expresiones culturales mediante las redes mundiales de conocimiento y de la información y, por otro, al surgimiento de los regionalismos e identidades que reivindican con fuerza lo particular. Junto con la difusión progresiva de la racionalidad productiva moderna aparecen nuevos lenguajes, renovadas sensibilidades culturales que se expresan con una vitalidad que descansa en la afectividad y en la revalorización de la vida íntima. Podemos observar un resurgimiento de la valoración de las formas éticas y culturales propias de cada pueblo, insertas desde tiempos ancestrales en la memoria colectiva, y que afloran en paralelo con la globalización unificadora. Es este clima posmoderno la vida privada se opone al éxito público como paradigma del logro en la biografía de los individuos.

Bajo esta perspectiva, estamos más al corriente de prácticas y sentidos culturales diversos. No obstante, enfrentamos una presión social para compatibilizar conductas sociales, económicas e incluso, políticas. En medio de esta constante polaridad, la migración es el fenómeno social que muestra más claramente dicha tensión.

Existen en el mundo 214 millones de migrantes, es decir gente que vive en un país distinto al de nacimiento. De estos 7,5 millones se encuentran en 
América Latina y el Caribe. O sea, un 3,5 por ciento del total. Los inmigrantes constituyen un 1,3 por ciento de la población de América Latina y el Caribe. Del total de inmigrantes un 18,4 por ciento se ubica en la zona caribeña, gran parte en Puerto Rico. Un 20,7 por ciento se concentra en América Central siendo Costa Rica el país que acapara un tercio de los inmigrantes, la mayoría nicaragüenses. Y un 60,9 por ciento se concentra en América del Sur. Del total de inmigrantes en esta parte del continente un 32 por ciento se localiza en Argentina; un 16 por ciento en Brasil; un 9 por ciento en Ecuador y un 7 por ciento en Chile (IM-UN, 2009).

A diferencia de las migraciones modernas del siglo $\mathrm{XX}$, que influyeron directamente sobre la formación social y demográfica de Latinoamérica marcadas por un carácter permanente y por consiguiente, con una orientación a la integración / asimilación prácticamente ineludible la movilidad humana internacional de este nuevo siglo se caracterizan por asociación a un imaginario de transitoriedad, lo que conduce a una mayor relevancia de los temas interculturales y mayor complejidad en cuanto a las disyuntivas que se presentan a los individuos y familias. Algunas de las tensiones las encontramos en la tendencia a, por un lado, renegar de sus orígenes; aferrarse con demasiada fuerza a ellos, lo cual dificulta el reconocimiento de la nueva sociedad; vivir entre dos mundos en forma ambigua o incorporar lo mejor (material y emocional) de cada cultura con el consiguiente enriquecimiento adaptativo y creativo.

\section{Migraciones internacionales en Chile: nuevos escenarios en el contexto de la posmodernidad}

En las últimas décadas del siglo XX, el subcontinente dejó de ser receptor de inmigración trasatlántica y se convirtió en expulsor de población hacia los países desarrollados, principalmente Estados Unidos, con profundos efectos en la economía, sociedad y la cultura de América Latina. En el caso de Chile hasta la década de los 70 sufrió pérdidas poblacionales debido a la migración principalmente hacia Argentina (razones económicas), luego se diversificó a EEUU, Venezuela, Brasil, Canadá y algunos países europeos por razones principalmente de exilio político. Las últimas cifras oficiales muestran que residen fuera de Chile 487 mil nacionales y 370 mil hijos de chilenos nacidos en el extranjero. ${ }^{2}$ Por cada 100 inmigrantes residiendo hoy día en nuestra tierra hay aproximadamente 140 chilenos, nacidos en nuestro suelo, que viven en tierras extranjeras.

${ }^{2}$ Instituto Nacional de Estadísticas y Dirección para la comunidad de chilenos en el exterior (INE-DICOEX), Registro de chilenos en el exterior, Santiago de Chile, 2005 , con base en los censos nacionales de población de 41 países seleccionados $\mathrm{y}$ el registro INE-DICOEX 2003-2004. 
En los años noventa el flujo emigratorio disminuyó considerablemente. Al mismo tiempo se inicia en Chile un proceso inmigratorio como consecuencia de un conjunto de factores tales como la reinstauración de la democracia, el crecimiento económico y la estabilidad política. A este fenómeno nuevo lo denominamos como migraciones en la posmodernidad.

Cuadro 1

EVOLUCIÓN DE INMIGRANTES EN CHILE: ALGUNOS PAÍSES DE AMÉRICA LATINA 1982 - 2009

\begin{tabular}{|l|l|l|l|l|l|l|}
\hline \multirow{2}{*}{$\begin{array}{l}\text { País de } \\
\text { origen }\end{array}$} & \multicolumn{6}{|c|}{ AÑOS } \\
\cline { 2 - 7 } & 1982 & 1992 & 2002 & 2009 & $\begin{array}{c}\text { Diferencia } \\
\%\end{array}$ & $\begin{array}{c}\text { Diferencia } \\
\%\end{array}$ \\
\cline { 2 - 7 } Argentina & 19.733 & 34.415 & 50.448 & 60.597 & $+46,5$ & $+20,1$ \\
\hline Bolivia & 6.298 & 7.729 & 11.649 & 24.116 & $+50,7$ & $+107,0$ \\
\hline Colombia & 1.069 & 1.666 & 4.095 & 12.929 & $+145,7$ & $+215,7$ \\
\hline Ecuador & 1.215 & 2.267 & 9.393 & 19.089 & $+314,3$ & $+103,2$ \\
\hline Perú & 4.308 & 7.649 & 39.084 & 130.859 & $+410,9$ & $+234,8$ \\
\hline Total países & 32.623 & 53.726 & 114.669 & 247.590 & $+113,4$ & $+115,9$ \\
\hline $\begin{array}{l}\text { Total } \\
\text { extranjeros }\end{array}$ & 84.345 & 114.597 & 184.464 & 354.344 & $+70,0$ & $+92,1$ \\
\hline
\end{tabular}

Fuente: elaboración propia sobre la base de los Censos de Población 1982, 1992 y 2002

Para 2009: elaboración basada en estadísticas del Departamento de Extranjería y Migraciones de Chile y Proyecciones de Población INE - DEM.

Las nuevas migraciones latinoamericanas que llegan desde los años noventa lo hacen en el contexto de globalización y posmodernidad. Es así como surgen nuevos temas y desafíos relevantes para nuestra sociedad, los cuales guardan relación, entre otras cosas, con la posibilidad de generar relaciones sociales con población migrante en torno a los principios de la pluralidad cultural que conduzcan a mayores grados de fraternidad humana. De esta forma es posible propiciar un proceso armónico de adaptación funcional, integración estructural, cohesión social con miras a otorgar posibilidades crecientes de identificaciones múltiples y no excluyentes, o sea, la identidad plural. La pluralidad cultural consiste en crear espacios de convivencia en los cuales las distintas comunidades se reconozcan como tales con la visibilización de sus diferencias mas también con apego a las normas de funcionamiento jurídico y social del espacio de acogida.

Chile vive desde hace un decenio un proceso inédito de migraciones externas de origen regional. Entre los censos de población y vivienda de 1992 y 2002 la población inmigrante aumentó en un 70 por ciento y entre el 2002 y 2009 
se incrementó en un 92,1 por ciento (ver cuadro 1). La tasa de crecimiento anual de este lapso es de 9,7 por ciento anual, el segundo más alto de nuestra historia, solo superado por el período 1875 - 1885. A la luz de las cifras que hemos sintetizado en el cuadro 1 hoy día residen en Chile poco más de 350 mil extranjeros. Un 37,1 por ciento son de nacionalidad peruana; un 17,2 por ciento argentinos; un 6,8 por ciento bolivianos; un 5,4 por ciento ecuatorianos y un 3,7 por ciento colombianos. Los mayores incrementos demográficos entre 2002 y 2009 pertenecen a los ciudadanos peruanos con un 234,8 por ciento y luego los ciudadanos colombianos con un 215,7 por ciento. ${ }^{3}$ La población extranjera representa actualmente el 2 por ciento de la población nacional, la proporción más elevada desde el censo de 1952.

A fines del siglo XIX y las primeras décadas del siglo XX llegaron a Chile inmigrantes europeos y asiáticos, árabes cristianos de Oriente Medio principalmente. Eran migraciones propias de la modernidad naciente con su racionalismo a cuestas. En las actuales migraciones en la posmodernidad su eje descansa en la comunidad afectiva. También, otra gran diferencia, es en el primer caso migrantes que cambiaban de ámbito de vida en forma definitiva, para iniciar un nuevo camino y por lo tanto sus descendientes se integraban al nuevo país haciéndolo suyo casi sin plantearse siquiera el sentido de pertenencia. En cambio, hoy en día, el proceso de las trasmigraciones y la irrupción de la era tecnológica y de las comunicaciones, hace posible vivir en un lugar geográfico distante y mantenerse al mismo tiempo aferrado a sus raíces originales. Este es a nuestro juicio la gran diferencia entre las migraciones en la modernidad y las actuales en la posmodernidad y globalización galopante.

Chile es un país básicamente mestizo, donde se funde principalmente sangre ibérica e indígena, si bien con una diversidad cultural pocas veces reconocida. Junto con ello, los aportes humanos de las migraciones durante la modernidad si bien reducidos en número, han sido claves para el desarrollo nacional. Con todo es tarea pendiente la de reconocer la identidad mestiza así como nuestra diversidad producto del aporte de grupos migrantes europeos, asiáticos y hoy día latinoamericanos como consecuencia de las migraciones en la posmodernidad. Sin embargo ha existido históricamente una representación imaginaria de una identidad homogénea nacional y que se abre con dificultad a la aceptación de distintas raíces y sus respectivos aportes constitutivos pluriculturales. La nueva realidad migratoria nos debe llevar a pensar con mucha profundidad de qué manera la llegada de nuevos grupos humanos están produciendo cambios en la sociedad chilena.

${ }^{3}$ En cuanto a los refugiados reconocidos en Chile la mitad, en torno a 900 , son de nacionalidad colombiana. 
4 El Uno es el origen, la no diferencia. Lo indecible, lo imposible de conocer, lo absoluto, lo no humano, el universo antes del principio del tiempo. El Uno es la reserva inagotable d energía en un estado puro. Es el símbolo de la aparición de lo esencial; principio activo que se fragmenta y da origen a la pluralidad. Se identifica con el centro, con el punto irradiante $y$ la potencia suprema. Es el Sol. El Dos es el reflejo, la contraposición. Para que el Uno sepa de su existencia le hace falta un referente. Ese referente está representado por el Dos, o sea es el espejo que le permite reconocerse que le permite reconocers al poder verse. Mientras no lo ve no sabe que existe. E Dos permite al Uno ampliarse, expresarse, ser conciente de su existencia. Es su semejante y su opuesto, su reflejo y su receptáculo. El Dos no puede separarse del Uno y el Uno no puede desarrollarse sin el Dos. Ahora bien, el Tres, nuestro Tres, corresponde a la evolución, es el tercer elemento que finalmente crea vida a partir de las energías estáticas e inmóviles que entrega el Uno yos. El Tres es la etapa yel movimiento, nace de la unión entre el Uno y el Dos. En el Tres se produce el encuentro a sí mismo, una vez que la imagen del espejo y el mismo no son más que un sola. En síntesis, en Uno la sola. En sintesis, en Uno la conciencia de que es y en Tres la vida se vuelve plenamente vida. Este número se relaciona con todo aquello que conlleva intercambio, comunicaciones y movimiento, por ejemplo el nomadismo y las migraciones en la posmodernidad. En una interpretación general el Tres se manifiesta a través de la libertad creadora, las facilidades para integrarse en el medio y los procesos de multiplicación ligados a la diversidad cultural. Simboliza también la liberación, la autonomía y la integración (Rossé, 2010).

Según el diccionario de símbolos (Cirlot, 1988) el Uno es el símbolo del ser, de la aparición de lo esencial. Es el principio activo que se fragmenta para originar la multiciplicidad y se identifica con el centro, con el punto irradiante y la potencia suprema. También simboliza la unidad espiritual, base de la fusión de tual, base de la fusion de
los seres. El Dos representa al eco, el reflejo, el conflicto, la contraposición; es decir la inmovilidad momentánea cuando las fuerzas son iguales. Simboliza el primero de los núcleos materiales, la naturaleza por oposición al creador, la luna comparada con el sol. Y el Tres se considera la síntesis espiritual. Es la resolución del conflicto planteado por

el dualismo. Asimismo es
Chile se encuentra en plena transición demográfica, caminado rápidamente hacia un país envejecido, con una fecundidad bajo el nivel de reemplazo, a diferencia de los países de la ruta migratoria andina (Colombia, Ecuador, Perú y Bolivia). Lo anterior, sumado a importantes diferenciales en los niveles de desarrollo y la mayor estabilidad política, redunda en un fenómeno migratorio que previsiblemente aumentará en los próximos años (ver cuadro 1).

Es importante y ya quizá urgente que Chile, en tanto Estado inserto en la comunidad latinoamericana y mundial, empiece a tomar conciencia plena de la necesidad de contar, no solo con una política migratoria adecuada a los nuevos tiempos de globalización e integración económica y cultural, sino que también se oriente a trazar líneas de acción basados en principios filosóficos. Es decir, más allá de analizar el fenómeno migratorio como consecuencia de condiciones objetivas materiales dispares entre países y lugares de origen y destino, es necesario reflexionar respecto del tipo de sociedad en el cual queremos vivir y las formas de incorporación de la población extranjera en nuestro ideario nacional. A nuestro juicio es ésta la discusión siempre pospuesta y nuestro llamado desde una postura fraterna es mostrar que Chile se ha formado social y culturalmente sobre la base de los aportes extranjeros y un amplio mestizaje. El problema ha sido, no obstante, la constante invisibilización de este rasgo social histórico y la reivindicación de un homogéneo imaginario que ha permeado nuestro pensamiento y acción. De ahí surge la dicotomía simbólica que proponemos entre la tendencia al Uno, que unifica, y el Tres que representa la diversidad. ${ }^{4}$

Las distintas contribuciones culturales fueron incorporadas al ethos nacional sin dejar espacio para la expresión de la diversidad comunitaria. Chile se representa en el imaginario colectivo como una nación unitaria en donde el factor orden, legalidad y homogeneidad cultural se han presentado siempre como pilares de la conformación del Estado - nación y el desarrollo. La nueva era posmoderna se caracteriza por la visibilización de la diversidad y el valioso surgimiento de todo aquello que simboliza el Tres como antípoda del Uno. Nuestro Tres posmoderno refleja la diversidad, la valoración de la socialidad - expresión de la importancia de aquello que otorga significado a las relaciones comunitarias basadas en el afecto y la cotidianidad de un estar juntos sin finalidad declarada y por el simple goce de compartir con el otro en un espacio de alta vitalidad - en medio de una comunidad emocional que se reconoce en una pluralidad cultural de identificaciones. 
La presencia de las colectividades extranjeras en Chile ha ofrecido un impulso al progreso y a la configuración de una nación con aportes multiculturales. Sin embargo, el peso de la tendencia homogeneizadora no ha permitido que sea incorporado debidamente al imaginario nacional. En un mundo globalizado y posmoderno, el valor de la diferencia tiende a acrecentarse y el surgimiento de los valores asociados al Tres debiese permitir, desde la pluralidad, potenciar nuestra sociedad con la fuerza de la diversidad de cada comunidad cultural comunitaria presente en Chile, sea esta originaria, de los descendientes de los migrantes en la modernidad o de los actuales migrantes latinoamericanos.

El proceso de construcción de la identidad nacional se realizó desde un ideario ideológico, en el cual se otorgaba a los inmigrantes europeos una superioridad antropológica. Se formó así en dos siglos el imaginario de un pueblo único y homogéneo.

Actualmente Chile vive un profundo cambio cultural. Comienza a valorizarse el reconocimiento de una identidad plural plena de identificaciones múltiples, en donde el reconocimiento de los nuevos inmigrantes cristaliza una sociedad plural marcada por la heterogeneidad. Lo distintivo de estas comunidades es su vinculación a un carácter esencialmente afectivo/emotivo que se fragua al interior de estas agrupaciones, socavando el imperio de la racionalidad instrumental.

En los migrantes en la posmodernidad se cumplen perfectamente los rasgos de esta nueva era con un agregado de suma importancia: el lugar atraviesa las fronteras y la distancia se reduce en función de lo afectivo. La mayoría de las veces el extranjero entrega nuevas energías a una sociedad desgastada por las formas lineales. Sin duda que Dionisos turba la perfección del orden apolíneo y facilita la aparición de nuestro Tres simbólico.

A lo largo de nuestra historia se buscó la asimilación de los inmigrantes a la sociedad nacional (el imaginario del Uno en la migración moderna). Hoy en día estamos en presencia de una migración en la posmodernidad de rasgos muy distintos pues comienza a predominar la ideología de la diversidad. Las fuerzas emergentes de la posmodernidad y el reconocimiento pluricultural de los grupos comunitarios de inmigrantes nos muestran una fuerte tensión entre las fuerzas de la unicidad y aquellas de la pluralidad.

La formación del Estado - nación en Chile fue configurado principalmente por la amalgama de todos los aportes culturales, tanto de la población aborigen

la resultante armónica de la acción de la unidad sobre el dos. Expresa el desenvolvimiento de la unidad en su propio interior (p. $329-330)$

En suma, para nuestra temática el Tres simboliza una correspondencia con todos aquellos significados que emanan de los movimientos migratorios, el diálogo intercultural, las emergentes comunidades emocionales, la socialidad, los valores dionisiacos. Representa pues aquellos desafíos que nos plantea la posmodernidad para la vida en comunidad en ambientes de diversidad y pluralidad cultural, mediante las migraciones internacionales que están cambiando el rostro de las sociedades contemporáneas. 
como de los grupos inmigrantes, en un sentido unitario y homogéneo, nuestro Uno, a pesar de las evidencias en el sentido de la multiculturalidad presente incluso durante el periodo colonial. Esto ha estado instalado, conciente o inconcientemente, en el imaginario chileno durante toda la historia republicana. Pensamos que esta visión de la uniformidad chilena no ha promovido destacar suficientemente estos aportes desde la diversidad cultural, los cuales sin duda alguna se puede reconocer en todas las esferas de la vida social. Nos inspiramos en este sentido y concordamos con Maffesoli (1991) cuando plantea que cada vez que una organización social ha colocado el acento en la diversidad ha sido fecunda y productiva. Ya sea en los aspectos culturales, en la estructura política o en la simple vida cotidiana.

El crecimiento de las migraciones durante estos primeros años del nuevo siglo ha sido una de las mayores en la historia de Chile. Aparece pues con fuerza el desafío el reconocimiento de una sociedad mestiza y multicultural. Los inmigrantes de la posmodernidad están fundando una sociedad de una vitalidad renovada, nos están mostrando el Tres, la pluralidad puesta al servicio del eterno retorno, de la no linealidad, de un diálogo social y cultural basado en la acentuación y valorización de las prácticas cotidianas. El fenómeno de las migraciones nos encuentra en un momento crucial pues resulta inevitable abordar el reconocimiento de una sociedad multicultural y el diálogo como método de acercamiento de los distintos grupos comunitarios convergentes en la sociedad chilena del nuevo siglo.

\section{Hacia la pluralidad cultural y la cohesión social}

La pluralidad cultural consiste en el respeto por la diversidad cultural comunitaria, el reconocimiento y espacios para que esas diferencias se manifiesten creativamente, junto con el acatamiento de principios básicos del ordenamiento jurídico y convivencia en la sociedad local. En la medida que ambos polos logren dar pasos hacia su contrario disminuirán las resistencias: una, la local chilena, con dificultad histórica y adosada a su genética social para aceptar la diferencia; otra, la de las comunidades de inmigrantes en sus diferentes momentos generacionales, con su tendencia a vivir aparte observando a la sociedad local como una estructura social rígida que segrega y marginaliza.

La pluralidad cultural solo puede darse mediante el diálogo fraterno entre las distintas comunidades. Conocer y promover las experiencias de diálogo 
intercultural ayuda a la integración y paz social. Conocer y respetar al otro en su diversidad reduce las posibilidades de hacerlos invisibles y discriminarlos. De igual forma el reconocimiento del otro - el nacional local en este caso por parte de los inmigrantes es también una necesidad y cobra sentido en un diálogo de esta naturaleza. Los cruces culturales tienen un terreno cada vez fecundo para los encuentros humanos. A pesar de que las fronteras siguen estando presentes una reconstrucción de su significado puede llevarnos a encontrar los puntos de interacción necesarios que estimulen cada vez más procesos de diálogo entre las distintas comunidades.

Quienes llegaron a Chile en la que hemos denominado como migraciones en la modernidad fueron pioneros y adoptaron esta nueva tierra como propia. Y de esa forma transmitieron a sus descendientes el amor por esta tierra, su segunda patria que se transformó finalmente en la propia. Actualmente las terceras y cuartas generaciones de descendientes, con amplio mestizaje, y ya integradas a Chile vuelven su mirada hacia sus raíces, al menos hacia alguna de ellas que les otorguen una singularidad a su identidad. Es la mirada hacia los orígenes, que revitaliza las nuevas generaciones descendientes de inmigrantes, es aquella búsqueda de sentido que radica en el movimiento migratorio de sus ancestros, una especie de unión entre vivencias arcaicas constelares y las necesidades de encontrar renovados sentidos de pertenencia e identificaciones múltiples. Es, en otras palabras, la libertad de darse la libertad del desarraigo.

Por otro lado, en estos procesos, la resiliencia afectiva como producto del nomadismo espacial juega un papel de importancia. O sea, una mayor capacidad para recuperarse por la pérdida de afectos, producto de las distintas posibilidades de la sociedad posmoderna donde el vitalismo comunitario se puede encontrar en las múltiples formas que encuentra la socialidad para acoger al individuo, haciendo de la afectividad comunitaria una fuente de oportunidades para aumentar la resiliencia.

Nuestro pasado nómada puede explicar ciertos rasgos atávicos de nuestro comportamiento, que a primera vista pudieran parecer inexplicables cuando se tiene a todo a mano, especialmente en las grandes urbes. Ese incesante interés en salir fuera de las fronteras nacionales, de encontrarse con otras culturas, otros idiomas u otros lenguajes. Para Giddens (2003) la aceptación del riesgo es también una condición de excitación y aventura. Una aceptación positiva del riesgo es la fuente misma de la energía que crea riqueza en una economía moderna y es un elemento esencial de una sociedad innovadora. Vivir en 
${ }^{5}$ Por ejemplo la llegada a Chile de inmigrantes cubanos y colombianos desde los años noventa ha permitido la introducción de la música y el baile afrocaribeño, lo cual luego de veinte años es posible decir que ha sido un innegable aporte a la cultura chilena desde una socialidad diferente, un "estar juntos" distintos; una forma de concebir fiesta con una perspectiva de grupo y baile por sobre el tradicional chileno que básicamente se centra en la conversación. una era global significa manejar una variedad de nuevas situaciones de esta índole. Esta disposición al riesgo implica una vitalidad renovada que es una de las características que destaca Maffesoli cuando se refiere al nomadismo. Dice: "Es natural establecerse, institucionalizarse, y por esto mismo, olvidar la aventura que marcó el origen. El nomadismo nos recuerda esa aventura original (...) el mito del caballero andante, sean cuales fueran las figuras contemporáneas que pudieran encarnar, continúa presente en el imaginario colectivo" (2004, p. 39). En este mismo texto este autor nos comenta que para Platón el inmigrante o el viajero se convierte en un riesgo moral innegable para el mantenimiento del status quo pues es portador de novedades y esto puede incomodar. El viajero es el testigo de un "mundo paralelo" donde lo afectivo, en sus diversas expresiones, se permite errar y en donde predomina la ausencia de normas. O sea, este inmigrante se transforma en un provocador - lo cual no quiere decir que sea un provocador cuando está en su medio de origen - que trastoca los valores de la sociedad de llegada y que con su forma novedosa de observar y participar en la vida se convierte en un ser distinto que puede, en el peor de los casos, ser objeto de discriminación, y en el mejor, de referencia de nuevas formas de socialidad en la sociedad de llegada. ${ }^{5}$

El nomadismo contemporáneo, desde nuestra perspectiva mediante los inmigrantes posmodernos, conforman una fuente de creatividad cotidiana. El hombre que vive en los márgenes (diferente de la marginalidad) de la vida social es en la posmodernidad quien está revitalizando la vida misma y ya no puede ser considerado como alguien ajeno y fuera de norma. Maffesoli dice en este sentido que así como el nomadismo ha participado en el desarrollo de civilizaciones anteriores es posible pensar que está contribuyendo a la construcción de una nueva realidad social contemporánea (2004).

Los inmigrantes de la posmodernidad están fundando una sociedad de una vitalidad nueva cuya integración social se basa en la acentuación de una vida en los márgenes. Cuanta diferencia se marca respecto de los inmigrantes en la modernidad que colocaron todo su empuje en fortalecer la unicidad, el ocultamiento de la diferencia y la aculturación, como parte de un proceso histórico el cual incluyó, por un lado, la visión unificadora del naciente Estadonación, y por otra, la necesidad de aquellos inmigrantes por pertenecer a una nación, a un territorio, buscando la no diferenciación.

Maffesoli (1992) plantea la presencia de una suerte de dualidad, donde el individuo se construye en el colectivo, así como la nación se construye en el 
contacto con una cultura distinta a sí misma. La diversidad, en la era de la globalización - entendida por la preeminencia de los valores democráticos; la emergencia de comunidades transnacionales y transterritoriales con base cultural; lo profuso y veloz nunca antes visto de los intercambios comerciales y financieros mundiales sin base cultural - se constituye en vector de desarrollo. En otras palabras, la pluralidad es el signo de la globalización posmoderna así como lo singular fue el objetivo en la era moderna. Al reflexionar sobre estas ideas Maffesoli nos muestra la potencia de lo diverso. Señala:

Inducida por el politeísmo, la imperfección relativa está en el corazón de todas las historias humanas, como es por lo demás lo propio de la vida. Las sociedades que han sabido preservarla han sido las más dinámicas. Al respecto, tal vez debe proponerse una "ley sociológica", la cual subrayaría que la armonía individual está aparejada con la vitalidad de un conjunto determinado. La organización social ha sido fecunda y productiva - en lo cultural, como en lo político o en la simple vida cotidiana - cada vez que ha sabido poner el acento en la diversidad. Hay que hacer notar que la figura de la sabia Palas Atenea, símbolo de la sabiduría que es llamada a manejar y guiar a la polis Atenas como prototipo de ciudad, es ella misma plural. Antes de ser la diosa de la razón y de la mesura es, según ciertas versiones, belicosa y salvaje (1992, pág.15).

Hoy los contactos entre culturas tienen cada vez más espacio de comunicación. Las fronteras siguen estando presentes. A pesar de esto, una reconstrucción de su significado puede llevarnos a encontrar los puntos de interacción necesarios que estimulen cada vez más procesos plurales desde una mirada intercultural.

\section{Los desafíos de una nueva era para las migraciones internacionales}

El fenómeno migratorio ha sido uno de los hechos históricos más significativos en el proceso de formación de las sociedades americanas, y más aún, ha sido un factor determinante en la conformación de nuestra sociedad mestiza. Sin embargo, producto de nuestra frágil memoria y a pesar de nuestra corta historia no hemos sido capaces de reconocer este origen, ni valorar el aporte y enriquecimiento cultural que han hecho a nuestra sociedad miles de inmigrantes venidos de culturas y sociedades diferentes, desde la Colonia hasta nuestros días.

Palobra No. 12. Agosto de 2010 - Julio de 2011 
En los tiempos actuales de posmodernidad y globalización es necesario revitalizarse como nación y pueblo e incorporar armónicamente los valores de la socialidad. Es sobre todo ineludible transitar desde la visión de la unicidad hacia la diversidad, desde lo apolíneo hacia lo dionisiaco, desde la lectura del uni-verso hacia el multi-verso. En definitiva, se trata de acoger con alegría, fe divina y humana la llegada del nuevo vástago, el Tres que traerá una imprescindible regeneración en la sociedad chilena de cara al nuevo centenario.

En Chile el aporte de los inmigrantes que llegan durante la modernidad ha sido claro. Los inmigrantes contemporáneos, nacidos de la posmodernidad, también lo están haciendo si bien su aporte por la ausencia de la perspectiva del tiempo es más difuso. Las sociedades cuando requieren de un nuevo dinamismo, y este es nuestro caso, necesitan cristalizar los variados aportes de los extranjeros. En definitiva la vida cotidiana no es más que una perpetua integración, consciente o no, de lo que viene de lejos, de la diversidad que se agrega primero en forma caótica y luego tiende a la cohesión en un todo reconocible.

El proceso de integración de los inmigrantes es un proceso largo y complejo. El escaso conocimiento del otro lleva al surgimiento de prejuicios, estereotipos y percepciones erradas con respecto a quien prácticamente no conocemos. Aparece entonces la discriminación, relegando al otro a un espacio prácticamente de "invisibilidad social y cultural" o generando una suerte de "vidas paralelas".

Para Sartori las sociedades modernas ven a los extranjeros como un otro demasiado diferente. Hace ver que el inmigrante es distinto respecto de los distintos locales, a los distintos a los que estamos acostumbrados, porque es un extraño distinto. Dice: "El inmigrante posee, a los ojos de la sociedad que lo acoge, un plus de diversidad, un extra o un exceso de alteridad" (2001, pág. 107).

La cohesión social corresponde a un de proceso de reconocimiento recíproco entre subjetividades, fundada en la referencia común en torno a modelos socialmente aceptados. Existe una confluencia entre las metas culturales, las oportunidades existentes para alcanzarlas y la formación de capacidades para alcanzarlas. Según Ottone y Hopeyhan (2005) la cohesión social corresponde a una dialéctica entre mecanismos instituidos de inclusión social y las respuestas, percepciones y disposiciones de la ciudadanía frente al modo en que 
ellos operan. Los mecanismos de integración e inclusión sociales incluyen, entre otros, el empleo, los sistemas educacionales, la titularidad de derechos, y las políticas pro-equidad, pro-bienestar y de protección social. En el otro lado, los comportamientos y valoraciones de los sujetos abarcan ámbitos tan diversos como la confianza en las instituciones, el capital social, el sentido de pertenencia y solidaridad, la aceptación de normas de convivencia, y la disposición a participar en espacios de deliberación y en proyectos colectivos. En la cohesión se afinca el sentido mismo de la ciudadanía, como disposición a participar en los asuntos públicos y como acceso a niveles de bienestar propios de un orden justo.

Estos autores enfatizan en la idea de que un desarrollo basado en la ciudadanía social conlleva la decisión de una sociedad que signifique un vivir entre iguales lo que no implica homogeneidad en las formas de vivir y pensar, sino una institucionalidad incluyente que asegure a todos las oportunidades de participar en los beneficios de la vida colectiva y en las decisiones que se toman respecto de cómo orientar esa vida colectiva.

En este sentido el aporte cultural de los inmigrantes y descendientes en Chile, ha significado un inmenso apoyo al desarrollo del país en sus casi 200 años de historia republicana. Con todo, los caminos de la inserción y visibilización cultural han sido complejos, y han tenido hasta hoy escaso reconocimiento en la formación de la sociedad chilena. Aún cuando Chile se encuentra en proceso de validación social de la multiculturalidad. Por lo mismo, es necesario avanzar con rapidez hacia mayores grados de comunicación entre las distintas culturas comunitarias. Una plena cohesión social de los diversos grupos culturales, sean inmigrantes o descendientes, enriquecen cultural y económicamente a las sociedades de acogida.

El desafío de Chile en una nueva era de migraciones en la posmodernidad se basa en la apertura social y mental hacia una sociedad plural y dialogante desde el ángulo cultural, basada en el nomadismo y las identificaciones varias. Es transitar hacia una sociedad inclusiva que acoja, reconozca e integre con mucha fuerza a la gente fuera del "topos", lugar, y así construir la "u-topía", lo que está más allá del lugar, de una sociedad más diversa y tolerante. El lazo dialéctico entre el necesario sedentarismo y la pulsión del "otro lugar", polos que marcan la tensión de la sociedad posmoderna, puede y debe constituirse en potente motor de una sociedad renovada, marcada por influencias culturales variadas y por el innegable empuje de nuevos grupos humanos. Más allá 
de los resquemores y temores de unos y otros, el encuentro de culturas a la larga siempre enriquece pues contiene la fuerza y la fe de un renacer en los inmigrantes y por parte de quienes acogen, la lucidez para reconocer la necesidad de imponer nueva savia en las raíces forjadas.

Chile se sitúa hoy día como el país más avanzado de América Latina y en el quintil de naciones más desarrolladas del mundo. Sin embargo en la representación social de este logro aparece una nación unitaria en donde el factor orden, legalidad y homogeneidad cultural se han presentado siempre como aspectos fundantes del desarrollo. Es extraña la escasa mención al aporte cultural comunitario diverso. O sea la energía subterránea ha mostrado como un Estado - nación se desarrolla en forma totalmente ajena al discurso oficial e incluso la percepción formal de las personas. De ahí la importancia del reconocimiento, valorización y visibilización de esta energías y el reconocer la importancia de la socialidad en el devenir de una nación.

El sinnúmero de pequeñas historias, tanto de comunidades extranjeras como de individuos, que han permeado lo social trasformándose durante nuestra historia en una suerte de mitología de encuentros culturales fructíferos mas siempre con una alta resistencia desde lo formal, desde lo social. Podemos decir que en este caso ha sido esa energía subterránea muy superior en fuerza y magnitud que la ideología de la unicidad. Nuevamente aparece la diversidad cultural como un aporte claro a la formación de una nación nueva y potente, pero que no acepta dicha multiplicidad y permanece con la representación social de que nuestro desarrollo se ha basado en una integración asimilacionista de diversas culturas - extranjeras u originarias - que se han expresado en Chile durante su historia independiente. Creemos que continuar con esta misma óptica monocultural frenará nuestro desarrollo pues la nueva era se caracterizará por la visibilización de la diversidad y la emergencia de todo aquello que simboliza el Tres como antípoda del Uno.

Es a contar de mediados del Siglo XIX que se empieza a hablar de modernidad. Cuando hoy hablamos de posmodernidad nos referimos a una nueva era que está en ebullición cuyos síntomas son cada vez más visibles. Decir posmodernidad es un término provisorio para decir que se ha iniciado el desplazamiento de la modernidad.

La sociedad moderna ha girado en torno al trabajo como la principal actividad humana sostén de todas las demás. Es por ello que las migraciones 
internacionales que hemos mostrado para Chile tenían como motivación central de atracción el factor trabajo. Chile en particular y el continente americano en general, disponían de tierras baldías y escasa población. Por lo mismo las migraciones que se inician justamente en el contexto de la emergencia de la modernidad europea llevan el signo del trabajo. Empero, las nuevas migraciones en la posmodernidad, si bien por cierto que arrastra el factor laboral puesto que sigue siendo importante, ya no es exclusivo para la decisión de emigrar o de permanecer en los lugares de destino.

Y el trabajo es una expresión de cálculo racional, razón que también se puede considerar como una de las características de la era moderna y que ha impactado en las humanidades ampliamente mediante el positivismo como el referente explicativo y prospectivo excluyente de la conducta humana, desechando las miradas intuitivas, cotidianas, en fin las de una sociología comprensiva en donde el imaginario de las sociedades e individuos se le diera equiparable importancia.

Junto con el trabajo y la razón aparece como rasgo central la fe en el futuro; es decir, lo que hacemos hoy es para un porvenir mejor, tanto para uno mismo como para la familia nuclear - otro de los pilares fundamentales de la modernidad que hoy tambalean con la emergencia y reconocimiento social de distintos tipos de familia - y en ese sentido los migrantes en la modernidad aparecen cumpliendo perfectamente las bases de aquella época. Fueron migraciones familiares en donde se avizoraba un futuro mejor para los hijos en una tierra de asimilación. Y el trabajo era el medio principal que daría las herramientas para ese logro. ${ }^{6}$

Las actuales tendencias de sociedad encuentran su cristalización en el proceso de globalización, el cual al darse conjuntamente con la posmodernidad, o sea ir más allá de hoy, da la oportunidad de vivir en una comunidad cada vez más ancha y vasta. El alcance de nuestros conocimientos e ideas avanza a una velocidad cada vez mayor y quienes pueden ser permeables a nuestras ideas, servicios y productos está solo limitado por el acceso a los medios de comunicación y la mayor o menor apertura al mundo global.

Que duda cabe que los tiempos están cambiando para los Estados naciones. La identificación excluyente solo con lo nacional, e incluso cultural, aparece cada vez más en las nuevas formas de relación social que refleja la socialidad posmoderna. Parece ser que el desafío de los tiempos que vivimos consiste en

${ }^{6}$ Con todo hay buenos ejemplos que hablan sobre como los migrantes árabe en Chile fueron precursores del posmodernismo sobre todo en su accionar nómada asociado al comercio en todo el territorio nacional (ver Agar, 2005). 
integrar habilidades sociales e individuales que permitan conciliar el ímpetu de la globalización, con la persistente manifestación de las múltiples diferencias valóricas y de sentido de vida, que presiona por una estandarización de los gustos y gestos, con la necesidad del sentimiento humano de sentirse perteneciente a una comunidad, a una cultura particular. Y a organizar su vida social en torno a principios éticos que reflejen un sentir colectivo y proponga, al mismo tiempo, un marco de acción propio a su cultura y que marque una identidad perfectamente reconocida por la sociedad global.

Coincide Castells (1999) con la sociología comprensiva - que recibe al posmodernismo como una época en la cual hay trazos de superación de la pretensión de verdad única mediante los clásicos métodos positivistas emanados del racionalismo - cuando asevera que la superación de las identidades, que era el gran proyecto histórico del racionalismo (liberal o marxista), ha sido superado por el renovado poder de la identidad. Y luego destaca el surgimiento de las identidades individuales al lado de estas identidades comunitarias que son autoconstruidas en torno a un proyecto personal, a un principio electivo. Es decir, una comunidad emocional la cual conserva rasgos de una comunidad con sus historias culturales sumado a las individualidades que otorgan un sentido de comunión al grupo desde una aproximación particular. La diversidad que explota con energía subterránea en la superficie de lo social y que transforma los hechos de la cotidianeidad en la vida misma.

Con la llegada de la globalización, el imaginario colectivo visualiza el mundo, a pesar de las evidentes diferencias, en forma cada vez más homogénea. Frente a la creciente tendencia por estandarizar la cultura surgen del vientre las voces pidiendo el respeto por las diferencias. He aquí la tensión dominante del conflicto de sociedades hoy en día latente.

El recuerdo de lo loable y la imagen de lo deseable comienzan a ser difusas, confundiéndose en el espumoso oleaje de las emociones compartidas cuando se desconocía la imagen y las formas de vida de los otros. Ahora, la oscilación del péndulo se inclina hacia el otro extremo: la visión de la vida se comparte menos a pesar de que la diversidad se conoce mejor. Esta entrega una cantidad de imágenes tan ricas que nos permite referenciar nuestras vidas y, de esa forma, apreciar o des-preciar la propia, sin mediar un intercambio real, personal.

Pareciera que se trata del secular principio de las polaridades, que señala que la búsqueda del equilibrio, cuando no se instala en el justo medio, se consigue 
a través de la presión en los ángulos contrarios. Así, pluralidad y diversidad se contraponen con el sino uniformador de la globalización.

Los valores de la modernidad han estado asociados con la sociedad democrática y occidental. Los valores de la posmodernidad, sin dejar de reconocer los logros de la modernidad, dan un salto desde la Unicidad hacia el Dos, su necesario espejo como una especie de trampolín para alcanzar el Tres en donde la vida se vuelve plenamente viva. Y es seguramente en este estadio en donde encontramos las reflexiones esclarecedoras acerca de la sociedad actual de Maffesoli, particularmente cuando se refiere a esa vitalidad subterránea que recorre la vida en comunidad y que, mediante la socialidad (el Tres) se erige por sobre (si bien también en forma complementaria) el Uno habiendo pasado por cierto por la fase moderna con los procesos de industrialización y urbanización que se reflejan en el Dos.

En la posmodernidad hacemos frente, con perplejidad las más de las veces, a un repliegue convulsivo, un retorno a las tradiciones del pasado, incluso al tribalismo, como resultados del proceso globalizador; una sinergia entre las formas arcaicas y el desarrollo tecnológico. Dicho de otra forma: en la cultura de la racionalidad reflexiva propia del mundo moderno se acude también al I Ching y al Tarot, a la Astrología, lugares donde confluyen naturalmente el conocimiento racional con el intuitivo, las emociones con las sensaciones. Frente a la racionalidad dominante, emerge lo mágico, lo no racional, lo trágico; todo aquello que no puede comprenderse a través de los marcos analíticos clásicos (Maffessoli y Agar, 2002).

Con relación a estas nuevas formas de vida, algunos pensadores de la posmodernidad sostienen que las actuales tendencias de la sociedad se cristalizan en el proceso de globalización, el cual no es un fin en sí mismo sino que es un medio actual de vivir en comunidad y en una cada vez más vasta, gracias a las redes virtuales que permiten mayores niveles de cercanía y contacto.

Estamos convencidos que, a pesar de la globalización que se manifiesta como una nube densa que dificulta la visión, sí existe un sustrato cultural latente que se evidencia a través de lo que denominamos la socialidad, es decir, todos aquellos momentos de interacción humana que escapan a una racionalidad con fines determinados y que, en cambio, responden más bien a la expresión de emociones emanados desde la comunidad.

PalObra No. 12. Agosto de 2010 - Julio de 2011 
Cuando prima lo social (el Uno) por sobre la socialidad (el Tres), la magia se pierde y el ser humano descubre que siempre ha necesitado la magia, los sueños, las creencias, inventar (se) ideas, ideologías, sistemas, religiones, valores y finalmente una ética: una conducta cotidiana socialmente aceptada.

Nos encontramos claramente en presencia de una verdadera cultura que intenta colocar en el terreno del juego social, estructurado y racional, los elementos de la socialidad, del juego de los afectos, del reconocimiento que la cultura global tiene que descansar sobre los cimientos de la diversidad, de la consideración debida de las distintas formas de vida en comunidad que, finalmente, ha permitido constituir la riqueza cultural de la humanidad. Así, nos enfrentamos a los desafíos de crear, es un acto sin duda creativo, en el seno de la cultura de la globalización y por sobre el dominio de lo social, una ética de la socialidad que reconozca el influjo decisivo de aquellas formas básicas de convivencia y juego de emociones colectivas al interior (y exterior) de la organización económica y social.

La movilidad se asocia con la dispersión. La dispersión con la segmentación. La segmentación con la diversidad. La diversidad con la cohesión (la unión plena del Tres con el Uno que da inicio a nuevas trinidades). Sentirse marginado de la sociedad en cualquiera de sus formas es una de las causas de la emigración. Así, movilidad y migración, sin significar lo mismo, se encuentran impregnados del mismo fenómeno humano: la atracción - por necesidad, obligación o deseo - de acercarse a otros seres humanos diversos y a otros lugares ignotos.

El término "movimiento" se asocia etimológicamente con émouvoir, que en francés significa emocionar. Es decir, el movimiento tiene que ver con la emoción. De ahí podemos decir que en el movimiento se expresa una emoción y en la movilidad espacial -y con mayor razón en la migración- estamos en presencia de una emoción vinculada al hecho de moverse en el espacio, cambiando, por motivos derivados de fuerzas externas o internas, el lugar de vida habitual.

Al llegar al nuevo ambiente iniciamos la lucha por adaptarnos funcionalmente al nuevo entorno, esta es la primera etapa de la socialización del migrante, bajo cualquier circunstancia. Al final de proceso, y expresado como una polaridad, aparece la aculturación, proceso mediante el cual el individuo adopta la cultura de acogida como propia $y$, por otro, el rechazo a la nueva sociedad y la automarginación. 
En medio se encuentra la vía de sincronizar los valores esenciales de la cultura de origen con la de destino, en el nuevo ambiente de vida. Comienza con la integración estructural; esta se produce cuando el individuo es capaz de expresarse emocionalmente en su nuevo espacio afectivo, cuando logra incorporarse a las redes sociales, ingresar a nuevas tribus en un territorio que lo sienta como propio, generar capital social y, por cierto, poder disponer de los distintos servicios públicos sociales. Y más reciente aún aparece el concepto de cohesión social el cual hace referencia no solo a la inclusión y participación de todos los miembros de la sociedad en la vida económica, social, cultural y política, sino que también al sentido de solidaridad y de pertenencia a la sociedad, fundado en el goce efectivo de ciudadanía y en una ética democrática. Incluye, pues, tanto los mecanismos instituidos de inclusión social (el empleo, los sistemas educacionales, la titularidad de derechos, y las políticas de fomento de la equidad, el bienestar y la protección social), como los comportamientos y valoraciones de los miembros de la sociedad (confianza en las instituciones, capital social, sentido de pertenencia y solidaridad, aceptación de normas de convivencia y disposición a participar en espacios de deliberación y en proyectos colectivos (MIDEPLAN, 2007)

\section{El surgimiento del tres: migrantes en la posmodernidad}

Es necesario desvirtuar aquella idea que apunta a decir que los inmigrantes frenan el desarrollo y constituyen una carga para el Estado. A la luz de la información que muestra la encuesta CASEN 2006 y 2009 es posible ver que esta noción del inmigrante no se ajusta a la realidad y más bien es todo lo contrario. Y pese a la inmensa dificultad para adaptarse a la nueva sociedad producen un aporte significativo a la economía, con su emprendimiento innovador, y también aportan a revitalizar la vida social, mediante una renovada socialidad, un uso distinto del espacio, nuevos sabores, música distinta, forma de hablar, gestualidad, en fin, todo aquello que hemos venido indicando a través de nuestra tesis central cual es la naciente realidad de heterogeneidad cultural que no es otra cosa que aquella energía subterránea que está haciendo transitar nuestra sociedad de la visión del Uno rígido, frío, al Tres diverso, cálido.

Las nuevas inmigraciones pueden hacer un enorme aporte al Chile posmoderno, al igual que lo hicieron las comunidades europeas, asiáticas y árabes en el siglo pasado, dejando una huella imborrable en el suelo chileno. Lo que puede marcar el sello de la cohesión plena, con identificaciones 
múltiples, es la vitalidad de estas nuevas comunidades que hacen de puente con otras culturas, abriendo así mayores espacios de comunicación y lazos afectivos, y también comerciales entre Chile y el mundo. Para García (2009) una inmigración exitosa es aquella donde los inmigrantes han logrado integrarse con tal efectividad en las redes locales, que no solo consigue revertir la condición de marginalidad original, sino que alcanzan posiciones de privilegio llegando a ser parte de la élite local. Incluso en ocasiones, esta clase inmigrante refunda la élite aportando en ella capital económico y cultural que legitima su posición. Este autor considera que Chile es un buen ejemplo de construcción histórica donde los inmigrantes, tras sucesivas oleadas, han construido una sociedad que experimenta permanentemente el tránsito de la incorporación de lo exógeno a la homogeneidad cultural. Señala que "así ha sido desde la llegada de los primeros españoles inmigrantes de la Conquista, hasta el arribo de inmigrantes árabes y judíos a principios del siglo XX. Chile es producto de una periódica mezcla de inmigrantes y cultura local" (p.215).

Finalmente el reconocimiento de la diversidad cultural comunitaria y las políticas públicas que se desarrollen en torno a este hecho social de la posmodernidad debería conducirnos hacia la implementación activa de formas de intervención social cuyo objetivo sea la cohesión social en la pluralidad. De esta forma se podrá promover que los nuevos inmigrantes u otras comunidades culturales locales, desarrollen una identidad plural o, mejor dicho aún, identificaciones múltiples. Es decir en vez de sentir la necesidad de reemplazar una forma cultural por otra, se apunta a enriquecer ambas formas constitutivas de su ser. Esto no debería significar en caso alguno renunciar a su cultura de origen y tampoco ausencia de responsabilidad para con la sociedad de acogida. El diálogo intercultural fraterno se instala como medio privilegiado para este logro.

\section{BIBLIOGRAFÍA}

Agar, L. (2005). Inmigrantes árabes en Chile, ¿Precursores del nomadismo posmoderno? en Diversidad cultural: El valor de la diferencia, 147 - 154. Santiago, Chile: LOM Ediciones.

Castells, M. (1999, mayo). Globalización identidad y Estado en América Latina. Separata sobre temas de Desarrollo sustentable. Santiago, Chile: Ministerio Secretaria General de la Presidencia de Chile, Programa de Naciones Unidas para el Desarrollo.

Cirlot, J. (1988). Diccionario de símbolos, Barcelona, España: Editorial Labor S.A.

IM-UN (2009). International migration. New York, USA: United Nations publication. 
Giddens, A. (2003). Un mundo desbocado. Los efectos de la globalización en nuestras vidas. Buenos Aires, Argentina: Taurus.

Maffesoli, M. (2004). El nomadismo: vagabundeos iniciáticos. México D.F, México: Fondo de Cultura Económica.

Maffesoli, M. (1992). La perfección del uno en Colección Pensamiento Social: La política y su doble. México D.F, México: UNAM, Instituto de Investigaciones Sociales.

Maffessoli, M. y Agar, L. (2002). El surgimiento de lo trágico y nuevas formas de insurrección social en Revista Acta Bioética, vol. VIII, No1. Organización Panamericana de la Salud: Naciones Unidas.

MIDEPLAN (2007). Cohesión social: Documento de reflexión XVII Cumbre Iberoamericana. Santiago, Chile.

Ottone y Hopenhayn (2005, 27 - 29 abril). Del desarrollo social a la cohesión social: algo más que un giro semántico en las propuestas de la CEPAL. Ponencia presentada en el ciclo de conferencias Tribuna de las Economías Latinoamericanas. París, Francia.

Rossé, J. (2010). El Eneagrama a la luz del simbolismo de los números. Barcelona, España: Obelisco. Sartori, G. (2001). La sociedad multiétnica: Pluralismo, multiculturalismo y extranjeros. Buenos Aires, Argentina: Taurus

Zlotnick, H. (2006). Tendencias de la migración internacional desde 1980 en Migraciones: Nuevas modalidades en un mundo en movimiento, 35 - 56. Barcelona, España: Antrophos Editorial. 